\title{
Memory in the iterative processes for nonlinear problems
}

\author{
Alicia Cordero $^{1}$, Neus Garrido ${ }^{2}$, Juan Ramon Torregrosa ${ }^{1}$, and Paula Triguero-Navarro ${ }^{1}$ \\ ${ }^{1}$ Universidad Politécnica de Valencia \\ ${ }^{2}$ Universidad Internacional de La Rioja
}

October 25, 2021

\begin{abstract}
In this paper, we study different ways for introducing memory to a parametric family of optimal two-step iterative methods. We study the convergence and the stability, by means of real dynamics, of the methods obtained by introducing memory in order to compare them. We also perform several numerical experiments to see how the methods behave.
\end{abstract}

\section{Hosted file}

MMAS_CMMSE_2021_TRIGUERO.pdf available at https://authorea.com/users/369649/articles/542963memory-in-the-iterative-processes-for-nonlinear-problems 